\title{
EPMA Studies of a New Ceramic Material for Machining Titanium Alloys
}

\author{
V. M. Bedekar,* D. G. Bhat,* S. A. Batzer,* L. R. Walker** and L. F. Allard** \\ *Department of Mechanical Engineering, University of Arkansas, Fayetteville, AR 72701 \\ **High Temperature Materials Lab, Oak Ridge National Laboratory, Oak Ridge, TN 37831
}

Titanium and its alloys are attractive materials in aerospace applications due to their unique high strength-to-weight ratios and their exceptional corrosion resistance. However, they are known to be difficult to machine due to their high reactivity and poor thermal conductivity, which leads to excessive temperatures in the tool and work-piece, and subsequent work hardening.

In this study a new ultra-hard ceramic material, $\mathrm{AlMgB}_{14}[1]$, was investigated as an alternative to conventional cemented tungsten carbide-cobalt, WC-6Co, for use as a cutting tool material. These two materials were tested against pure $\mathrm{Ti}$ and a Ti alloy, and two Fe-containing alloys for which the WC material has acceptable performance. The relative degree of reaction between each of the tool and work-piece materials, after high temperature treatments, was characterized using a JEOL JXA 8200 electron probe microanalyzer. Specimens were prepared by sandwiching the cutting tool material between the work-piece materials, and clamping the sandwich in a Kovar fixture. These assemblies were then sealed in quartz capsules under argon, and the capsules were heated at $1000^{\circ} \mathrm{C}$ for 120 hours. The low thermal expansion coefficient of Kovar allowed sufficient compressive pressure to be generated at the tool/work-piece interface to ensure intimate contact for interdiffusion.

Initial examinations using backscattered electron imaging showed that some interactions occurred at all tool/work-piece interfaces. However, the extent of the interaction varied from tens of microns in the Ti-containing materials/AlMgB 14 and Fe-containing materials/WC-6Co (Figs. 1,4), to hundreds of microns in the Ti-containing materials/WC-6Co and Fe-containing materials/AlMgB 14 (Figs. 2,3). Quantitative line scans for constituent elements confirmed boron as the primary diffusive element when $\mathrm{AlMgB}_{14}$ was present (Figs. $1 \mathrm{~b}$ and $3 \mathrm{~b}$ ), and carbon as the primary diffusive element when WC-6Co was present (Figs. $2 \mathrm{~b}$ and $4 \mathrm{~b}$ ). The most significant diffusion occurred with the $\mathrm{AlMgB}_{14}$ and Fe-containing materials and the least with the WC-6Co and Fe-containing materials.

We can draw the following conclusions from this work: 1) $\mathrm{AlMgB}_{14}$ reacts with titanium and the alloy Ti-6Al-4V to a significantly lesser extent than does the WC-6Co material. The primary interaction mechanism appears to be diffusion of the boron into the work-piece along grain boundaries, and the subsequent formation of borides. 2) $\mathrm{AlMgB}_{14}$ reacts strongly with $\mathrm{Fe}-10 \mathrm{Ni}$ and $\mathrm{Fe}-\mathrm{Cr}-\mathrm{Ni}$, leading to formation of borides and aluminides. 3) WC-6Co shows little reaction with Fe$10 \mathrm{Ni}$ and $\mathrm{Fe}-\mathrm{Cr}-\mathrm{Ni}$. The interaction involves partial decomposition of the WC-6Co and diffusion of $\mathrm{C}$ and Co. 4) WC-6Co reacts strongly with Ti and Ti-6Al-4V. Based on relative reactivity and interdiffusion, these results show that $A l M g B_{14}$ has strong potential as a cutting tool for titanium and its alloys. [2]

\section{References}

[1] B.A. Cook, J.L. Harringa and A.M. Russell, U.S. Patent 6,099,605 (2000).

[2] Research sponsored by the Assistant Secretary for Energy Efficiency and Renewable Energy, Office of FreedomCAR and Vehicle Technologies, as part of the High Temperature Materials Laboratory User Program, Oak Ridge National Laboratory, managed by UT-Battelle LLC for the US Department of Energy. 

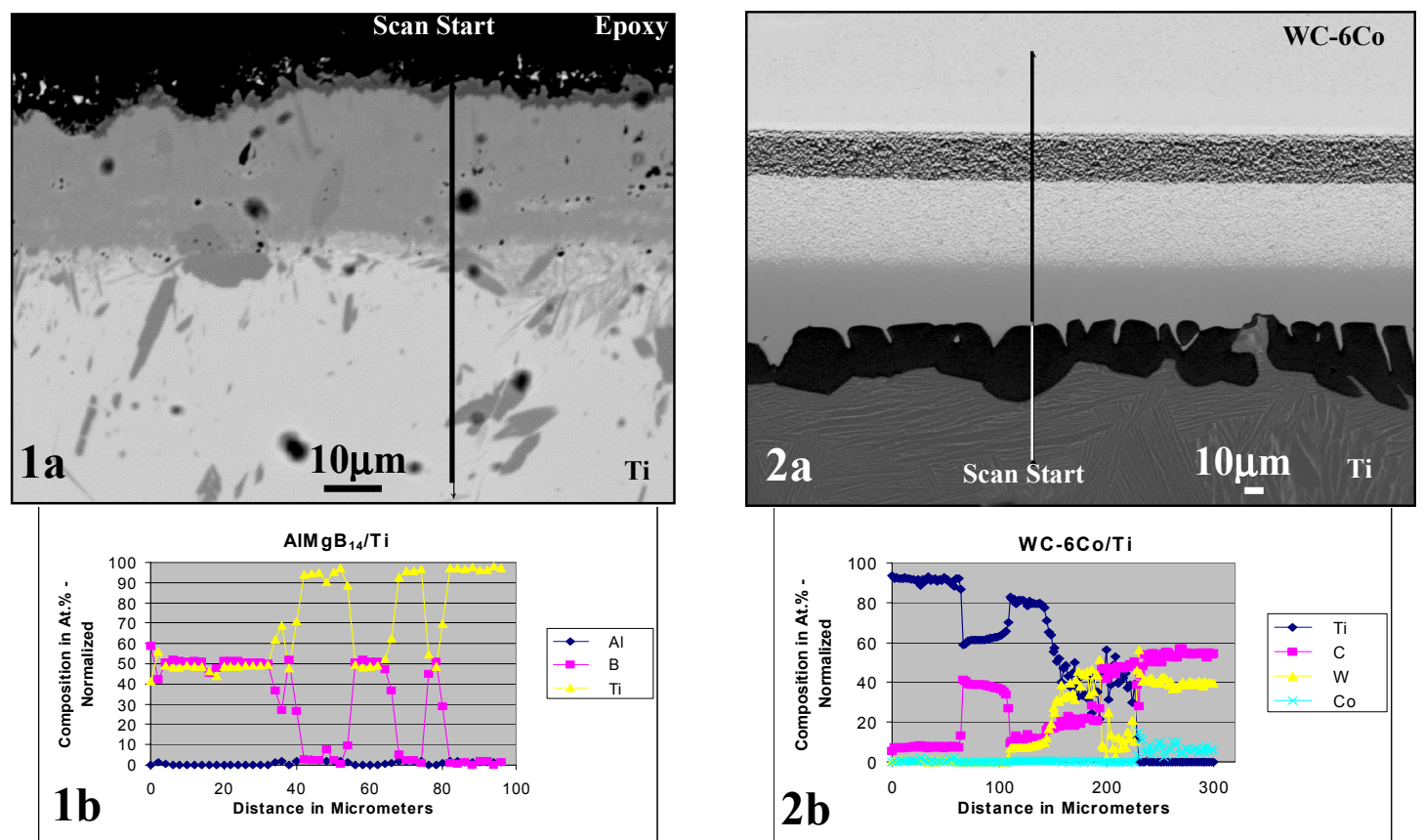

FIG.1. a) Work-piece side (tool separated) $\mathrm{AlMgB}_{14} / \mathrm{Ti}$ interface showing $\sim 30$ micron reaction zone, and deeper boride precipitates . b) Line scan data through reaction zone.

FIG.2. a) WC-6Co/Ti interface showing $\sim 150$ micron of reaction and diffusion zones. b) Line scan through reaction and diffusion zones.
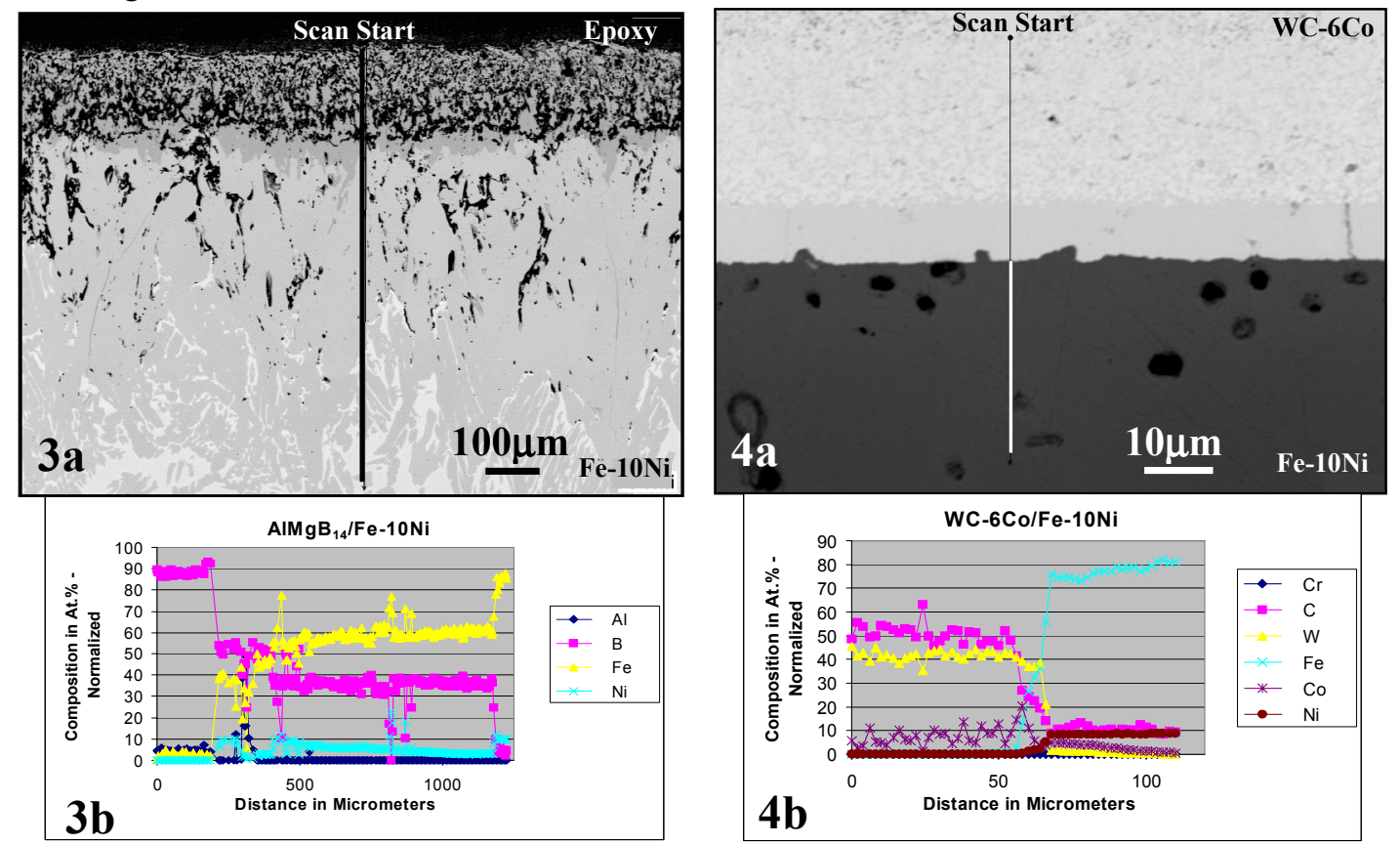

FIG. 3. a) Work-piece side (tool separated) $\mathrm{AlMgB}_{14} / \mathrm{Fe}-10 \mathrm{Ni}$ interface showing $>1000$ micron reaction/diffusion zones. b) Line scan data through reaction and diffusion zones.

FIG. 4. a) WC-6Co/Fe-10Ni interface showing $\sim 10$ micron reaction zone and diffusion zone. b) Line scan data through reaction and diffusion zones. 